\title{
Using a Trauma-Informed Practice Framework to Examine How South Australian Judges Respond to Trauma in the Lives of Aboriginal Defendants
}

\author{
Katherine J. McLachlan ${ }^{\mathrm{a}}$
}

${ }^{\text {a}}$ Flinders University, Adelaide, Australia

\begin{abstract}
This article uses a trauma-informed practice framework to examine how South Australian superior court judges acknowledge defendant trauma when sentencing Aboriginal defendants. Trauma-informed sentencing requires that judges realise the presence of trauma, recognise its relevance, respond in a way that is informed by trauma and act to avoid re-traumatisation. By analysing sentencing remarks of 42 defendants identified as Aboriginal, the presence of trauma-informed practice was explored, in terms of judicial decision-making, the sentencing process and the sanction imposed. While not holistic summaries of judges' reasoning, sentencing remarks are intended to enable the parties and the community to understand sentencing logic. Analysis indicated that judges realised trauma was present in the lives of many Aboriginal defendants but did not always overtly recognise a link between trauma and criminal behaviour and were unlikely to refer to a defendant's trauma history or use trauma-informed principles of practice in their sentencing response.
\end{abstract}

JQCJC "Qualitative Criminology," (2022)

Vol. 11, Iss. 2, 181-210

ARTICLE HISTORY Received 3/1/2021 Accepted 8/30/2021

\section{KEYWORDS}

Aboriginal defendant, sentencing, trauma

This article used an established trauma-informed practice framework to examine how judges of South Australian superior courts acknowledged defendant trauma when sentencing Aboriginal defendants. Trauma in the lives of people who offend (as both an experience and the impacts of those experiences) is prevalent (Malvaso et al., 2021; Ministry of Justice, 2013; Wolff \& Shi, 2012), and the compounded effects of collective and direct trauma experienced by Aboriginal defendants is notable (Menzies, 2019). Australian Aboriginal people are highly resilient in the face of collective trauma experiences that undermine their cultures and identity. Nevertheless, the impacts of unresolved trauma increase the likelihood that people will engage in harmful and criminalised behaviour, such as substance abuse, violence, and aggression (Australian Law Reform Commission [ALRC], 2017; Atkinson, 2008). Aboriginal people face

DOI: https://doi.org/10.21428/88de04a1.04778d50 
disproportionately high levels of social exclusion, poverty, homelessness, and racism (Atkinson et al., 2014), and this disadvantage is associated with criminal justice system engagement (ALRC, 2017; Freiberg et al., 2016). Current sentencing approaches based on specific deterrence and individual responsibility are limited in their effectiveness when responding to people with complex and compound trauma. I am particularly aware of the limitations of traditional justice responses to defendants from my experience as a member of the Parole Board of South Australia. I have interviewed hundreds of people who offend who have experienced multiple, complex, and sustained trauma. Trauma-informed sentencing may be regarded as a form of therapeutic jurisprudence (McLachlan, 2021), actively targeting the underlying causes of crime to reduce future crime. Yet, there is a lack of understanding of how defendants' trauma histories influence sentencing.

\section{The Significant Impacts of Unresolved Complex Trauma}

There is no universally accepted definition or understanding of trauma (Walklate, 2016). In fact, "(i)t remains contentious among mental health professionals as to whether 'trauma' relates to a single event or series of events, an environment, to the process of experiencing the event or environment, or to the psychological, emotional, and somatic effects of that experience" (Atkinson et al., 2014, p. 291). The US's Substance Abuse and Mental Health Services Administration states that individual trauma "results from an event, series of events, or set of circumstances that is experienced by an individual as physically or emotionally harmful or life threatening and that has lasting adverse effects on the individual's functioning and mental, physical, social, emotional, or spiritual wellbeing" (SAMHSA, 2014, p. 7). This is the understanding of trauma on which this article is based.

Complex trauma is the cumulative or compounded impact of multiple and/or prolonged traumatic stressors (Higgins \& McCabe, 2001), leading to "underlying" dysfunction across a person's life (Kezelman \& Stavropoulos, 2019, p. 80). Complex trauma experts, Kezelman and colleagues, identify all developmental trauma (i.e., chronic trauma experienced in childhood) as complex because it changes the developing brain "from a 'learning' brain to a 'survival' brain" (Kezelman et al., 2015, p. 14). Because complex trauma may be caused by a range of stressors, its symptoms and impacts are varied, including changes in "personality structure," psychological trauma symptoms, neurological trauma, and emotional trauma (Wall \& Quadara, 2014, p. 3, see also Kezelman \& Stavropoulos, 2019). Developmental trauma may include adverse childhood experiences (ACEs), that is, psychological abuse, physical abuse, sexual abuse, household substance abuse, household mental illness, domestic abuse, incarceration of a household member, emotional or physical neglect, or parental separation/divorce (Felitti et al., 1998; Reavis et al., 2013). The negative effects of ACEs are often compounded 
"Qualitative Criminology" Using a Trauma-Informed Practice Framework to Examine How South Australian Judges Respond to Trauma ...

such that the more ACEs experienced by an individual, the poorer their physical and mental health outcomes and the greater their likelihood of substance abuse (Felitti et al., 1998) and criminal behaviour (Reavis et al., 2013).

Unresolved trauma is the impact of untreated and unaddressed complex trauma, resulting in interrupted neurological, social, and emotional development (Kim et al., 2014; van der Kolk, 2005), "when no effective opportunity [has been] provided ... to make sense of these experiences" (Boswell, 2016, p. 16). If developmental trauma remains unresolved, it can be entrenched or exacerbated by traumatic experiences later in life (Cloitre et al., 2009). Unresolved trauma may also lead to the retention of coping mechanisms that may have been protective in the short term but are maladaptive in adulthood, such as hypersensitivity to triggers and perceived threats (Jones, 2018; van der Kolk, 1987). Chronic, ongoing trauma leads to significant "changes in mind, emotions, body, and relationships ... including severe problems with dissociation, emotional dysregulation, somatic distress [and] relational or spiritual alienation" (Ford \& Courtois, 2014, p. 13). Because Australian Aboriginal people are also dealing with the cumulative impacts of historical, collective and intergeneration trauma, direct experiences of complex trauma are often compounded by intergenerational trauma.

\section{Realising Trauma Experienced by Australian Aboriginal People}

Complex trauma (particularly developmental trauma) experienced by Aboriginal people is often exacerbated by-and a product of-intergenerational trauma, (i.e., trauma "across familial generations"; Menzies, 2019, p. 2; see also: Minh et al., 2013; Kezelman et al., 2015). Intergenerational trauma is prevalent in families where Aboriginal and Torres Strait Islander children were forcibly removed from their families and communities (Shiosaki, 2020; Menzies, 2019). Aboriginal children who were forcibly removed are referred to as "the Stolen Generations." This intentional destruction of culture and family is also reflected in the collective and historical trauma experienced by First Nations peoples in other countries, such as Canada (see: Bombay et al., 2009). Collective trauma is caused by "structural, social, economic, and political" disadvantages experienced by Aboriginal people (Quiros et al., 2019, p. 160). Historical trauma "flows from systematically inflicted and sustained trauma on a subjugated population" (Menzies, 2019, p. 1), and continues to impact Aboriginal people, after years of being denied access to their languages, laws (and lore), traditions, cultures, lands and sacred places, and ways of life (Dodson, 1997; Bombay et al., 2009). Since colonisation, the Australian Government's systematic dismantling of cultural links and destruction of identity and a sense of belonging (ALRC, 2017) has resulted in Aboriginal people experiencing "social disintegration (i.e., identity confusion between dominant and original culture) and social disadvantage" (Hill et al., 2010, p. 40). Statements such as that made by Prime Minister Scott Morrison in 2021 that 
the day the First Fleet arrived in Australia in 1788 "wasn't a particularly flash day for the people on those vessels either" (Hytner, 2021), minimise the importance of acknowledging the devastating impact that British settlement has had on Australian Aboriginal people and their cultures. Historical and collective trauma experiences exist in the living memories and "soul wounds" (Bombay et al., 2009, p. 23) of Aboriginal people today such that the impact of these de-humanising policies and statements cannot be underestimated.

\section{Recognising the Relationship Between Trauma Histories of Aboriginal People and Criminal Behaviour}

Aboriginal people are over-represented in the justice and child protection systems, and face disproportionately high levels of social exclusion, poverty and homelessness, racism, and substance abuse (Atkinson et al., 2014). As identified by Caroline Atkinson (2008), an Aboriginal woman of Jiman and Bundjalung heritage, the cumulative trauma experienced by Aboriginal people has "led to a self-destructive cycle of loss of identity and purpose that fuels anger and trauma behaviours, such as acts of violence and alcohol and drug misuse" (p. 7). Data indicate that interpersonal violence, including domestic abuse and family violence, is significantly higher for Aboriginal people than non-Aboriginal people (Productivity Commission, 2016). Karen Menzies (2019), a Wonnarua woman, recognises the many links between trauma and criminal justice system involvement, including "violence against women; self-directed violence, suicide and risk-taking behaviour; substance abuse; ... [and] sexual abuse" (p. 1528). People who are members of the Stolen Generations are more likely to have been charged, arrested, and imprisoned and been the victims of violence than Aboriginal people who were not forcibly removed from their families (Australian Institute of Health and Welfare, 2018). In their study of 41,700 children and young people in Queensland, Anna Stewart and colleagues (2002) found that Aboriginal and Torres Strait Islander children were more likely to have experienced child abuse and neglect, particularly chronic child abuse and neglect, and were four times more likely than their non-Indigenous peers to offend.

Research has found that the over-representation of Indigenous people in prison can be attributed to extensive criminal histories (associated with social exclusion and trauma) rather than any inherent racism in judicial decision-making (Bond \& Jeffries, 2013). Indeed, in South Australian higher courts, Aboriginal defendants were found to be less likely to receive a custodial sentence than their non-Indigenous peers (Jeffries \& Bond, 2009), possibly due to a greater acceptance of the presence of mitigating factors. The High Court decisions of Munda v Western Australia (2013) and Bugmy v The Queen (2013) raised the issue of Aboriginality as a sentencing consideration. The majority in Bugmy stated that, "(a)n Aboriginal offender's deprived background may mitigate the 
"Qualitative Criminology"

sentence that would otherwise be appropriate for the offence in the same way that the deprived background of a non-Aboriginal offender may mitigate that offender's sentence" (at p. 592-4 [para. 37] per French CJ, Hayne, Crennan, Kiefel, Bell, Keane JJ). Trauma associated with Aboriginality is slowly being recognised by lower courts as relevant in sentencing. In $R v$ Grose (2014), while Aboriginality per se was not seen to be relevant in sentencing, Justice Gray made the uncommon step of acknowledging the intergenerational impact of Aboriginal people being removed from their families and communities (with Sulan and Nicholson JJ concurring). Other types of trauma, such as developmental trauma and exposure to intergenerational alcohol abuse, have been recognised specifically in the sentencing of Aboriginal defendants (see: $R v$ Pennington (2015)). In $R \vee$ Nelson (2017), the SA Court of Criminal Appeal acknowledged that Aboriginality is more than simply a mitigating factor. They stated, "[i]t is also proper for the court to recognise the problems within Aboriginal communities and that the cure often requires more subtle remedies than the criminal law can provide by way of imprisonment" (at para. 26).

However, Justice Gray, like the High Court, argued that the emphasis should be on individualised justice rather than the recognition of collective trauma experienced by people because of their Aboriginality. He said:

... risk factors associated with criminal offending such as unemployment, lack of education and poor health, which inhibit full participation in community life, are far more prevalent in relation to Aboriginal people. While these statistical facts say nothing about an individual before a sentencing court, the fact that they are a relatively common experience of Aboriginal defendants suggests a need for a sentencing court to be alive to the likelihood of their existence, to explore whether they are present, and, if they are, to explore their relevance to the offence and offender. The need to achieve individualised justice requires as much. Doing so may require that the court adopt a proactive approach. Again, that is not to single out Aboriginal defendants for special treatment. The same sort of approach could be required in myriad circumstances involving defendants of different ethnicities and backgrounds. ( $R \vee$ Grose at para. 41 )

These decisions suggest that Australian courts are beginning to recognise the relevance of complex and developmental trauma on criminal behaviour but remain reticent to acknowledge any inherent trauma associated with how the government and community respond to Aboriginal people. These cases indicate that current judicial practice may be partially informed by trauma, even in the absence of an intentional, trauma-informed framework. 


\section{Responding to Trauma and Trauma-Informed Sentencing}

The concept of 'trauma-informed' first emerged 20 years ago in the work of Maxine Harris and Roger Fallot (2001). Trauma-informed practice is not designed to treat or resolve trauma; rather, it enables service providers at all levels of an organisation to be aware of the impact of trauma on a person's behaviour and functioning and to promote service environments conducive to recovery that avoid further traumatisation. Trauma-informed practice may be defined as the application of "basic knowledge of the impacts of stress on the brain and body and strategies to avoid exacerbating possible trauma-related problems" (Kezelman and Stavrolpoulos, 2016, p. 5). Thus, to be trauma-informed is to understand the potential ongoing and complex effects of traumatic events on an individual's ability to function and interact with the world around them.

When applying the trauma-informed framework to practice, a service is required to "recognize, understand and minimize" the long-term impact of trauma (Kubiak, Covington \& Hillier, 2017, p. 92). This has been articulated as four key assumptions-to realise, recognise, and respond to trauma and resist re-traumatisation-by SAMHSA (2014, p. 9f), as per Figure 1.

A trauma-informed response (Step 3 in the framework) requires the application of six key principles: safety; trustworthiness and transparency; peer support; choice and empowerment; collaboration; and recognition of cultural, historical and gender issues (Covington, 2016; Fallot \& Harris, 2011; Harris \& Fallot, 2001; Henderson, Everett \& Isobel, 2018; Kezelman \& Stavrolpoulos, 2019; SAMHSA, 2014). The Safety principle aims to provide effective and consistent physical and emotional safety to service users when they access services; ensure service users feel welcome, included, and heard by the service provider; and educate users and workers regarding client rights, feedback processes, as well as protective policies and practices. Trustworthiness and transparency refer to the establishment of mutually understood, clear and consistent expectations and boundaries, such that a relationship of trust may be built between the service provider and the service user. Peer support emphasises the importance of involving individuals with lived experience of trauma when responding to clients with trauma. Choice and empowerment involve providing service users with control regarding their service preferences. This is done through information, options, and an awareness of users' rights and responsibilities, as well as promoting skill-development of service users through a strengths-based approach. Collaboration requires that service users be provided the opportunity to participate in the planning and shared decision-making around activities and settings related to service provision (Fallot \& Harris, 2011, Kezelman \& Stavrolpoulos, 2019; SAMHSA, 2014; McLachlan, 2021). Finally, SAMHSA (2014) 
highlights the importance of recognising the significance of culture, history, and gender when designing a trauma-informed service response.

Figure 1: Trauma-Informed Practice Framework

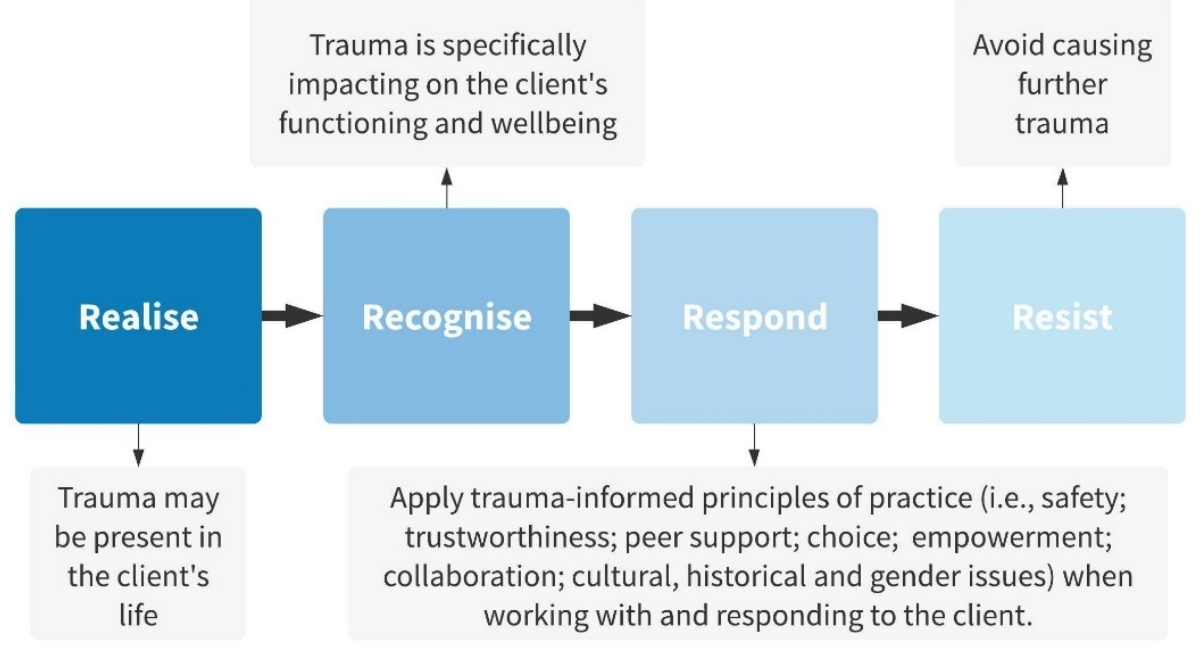

These trauma-informed principles may be applied to the sentencing process such that safety, for example, is present when the courts ensure that defendants feel included, able to participate and be heard. Trustworthiness and transparency are demonstrated when judges ensure that defendants understand both the court process and the implications of the sentencing decision. Peer support may be achieved through Aboriginal Conferences, where Elders, community and family members can participate in the sentencing process and express their views (ALRC, 2017, Sentencing Act 2017, s. 22). Choice requires that courts recognise defendants' rights, such as when judges discuss conditions of a bond with a defendant to ensure the individual understands and can comply. Empowerment is best demonstrated when rehabilitation is prioritised by the courts, as well as through statements that recognise the importance of individual strengths and characteristics. Collaboration with defendants is difficult to demonstrate in sentencing. Arguably, shared decision-making is not possible in mainstream courts, although defence counsel is able to present to the court individual factors that the defendant believes are relevant to sentencing and the defendant's preferred outcome. Finally, a defendant's culture, history, and gender should be given regard in sentencing when discussing the individual factors that impacted offending behaviour (see: Fallot \& Harris, 2011, Kezelman \& Stavrolpoulos, 2019; SAMHSA, 2014). 


\section{Method}

Sample

Sentencing remarks relating to 448 defendants were downloaded from South Australia's Courts Administration Authority website, from 1 May 2019 to 30 November 2019 inclusive, capturing most decisions within that timeframe (excluding remarks not published). Sentencing remarks can provide insight into the decision making of the courts, assisting the parties and the community to understand the logic and reasons behind a sentencing decision (Judicial College of Victoria, 2020). They provide a glimpse into the minds of judges at work, making decisions about the most appropriate sanction to impose in response to a finding of guilt. While sentencing remarks may not reflect judges' complete thought processes, they offer the best resource to measure judges' professional views and the elements that influence their decision-making.

A manual review of the sentencing remarks led to the recognition of 42 defendants who were identified by judges as Aboriginal. The 42 Aboriginal defendants represented 9.4 per cent of the original sample. Aboriginal people make up two per cent of the South Australian population (Australian Bureau of Statistics, 2019) and 23.8 per cent of South Australia's average daily prisoners (Productivity Commission, 2021). Aboriginal cultural groups are not homogenous, and in a minority of cases, judges specifically recognised Kaurna, Narrunga, Ngarrindjeri, Anangu (Pitjantjatjara), Adnyamathanha and Kokatha people, respectively. The number of defendants identified by judges as Aboriginal is an underestimation as judges often did not refer to the defendants' racial or cultural background (and I know from Parole Board interviews that other defendants in the sample are Aboriginal). Thus, the sample is a subset of defendants who judges explicitly acknowledged as Aboriginal people. All defendants and judges were de-identified.

\section{Analytical Approach}

Sentencing remarks were analysed using thematic and content analysis (Braun \& Clarke, 2006). Using the SAMHSA (2014) trauma-informed practice framework, sentencing remarks were reviewed to determine where judges:

- $\quad$ realised the presence of traumatic stressors in defendants' lives;

- recognised how the impact of traumatic stressors has led to or influenced defendants' criminal behaviour;

- $\quad$ responded (through the sentencing process and sanction) to mitigate the effects of unresolved trauma on future criminal behaviour; and

- resisted future re-traumatisation and promoted rehabilitation through traumainformed sanctions (McLachlan, 2021). 
In identifying trauma in sentencing remarks, "manifest content" (i.e., the overt, "visible, surface content") was used, rather than inferring any underlying or latent meaning to the judges' reasoning (Maxfield \& Babbie, 2006, p. 266). The entire sample of sentencing remarks was manually coded using inductive codes from existing trauma measures as per Table 1 below (see also Berryessa, 2021), as well as deductive keywords, such as "trauma," "upbringing," "hardship," and "chronic." There were 233 defendants with trauma histories identified using these codes, of whom 37 were identified by judges as Aboriginal (15.9\% of the traumatised sample). Neither collective, historical nor intergenerational trauma were codes as they were not acknowledged in any sentencing remarks.

\begin{tabular}{ll}
$\begin{array}{l}\text { Table 1: Coding to Identify Where Judges Realised and Recognised Trauma in Sentencing } \\
\text { Remarks }\end{array}$ \\
\hline $\begin{array}{l}\text { ACES } \\
\text { (Felitti et al., 1998; Reavis et al., 2013) }\end{array}$ & $\begin{array}{l}\text { Life Events Checklist } \\
\text { (Weathers et al., 2018) }\end{array}$ \\
\hline Psychological abuse & Natural disaster, fire, explosion \\
Physical abuse & Car, motorbike, or workplace accident \\
Sexual abuse & Physical assault with or without a weapon \\
Emotional and/or physical neglect & Sexual assault or abuse \\
Household substance abuse & $\begin{array}{l}\text { Combat or exposure to war } \\
\text { Household mental illness }\end{array}$ \\
$\begin{array}{l}\text { Captivity (for example, being kidnapped, abducted, } \\
\text { held hostage, prisoner of war) }\end{array}$ \\
$\begin{array}{l}\text { Exposure to domestic abuse } \\
\text { Household member absent (due to incarceration or orening illness or injury } \\
\text { parental separation/divorce) }\end{array}$ & $\begin{array}{l}\text { Serious injury, harm, or death you caused to } \\
\text { someone else }\end{array}$ \\
& $\begin{array}{l}\text { Sudden death and associated grief and loss } \\
\text { Any other very stressful event or experience }\end{array}$ \\
\hline
\end{tabular}

There were six defendants identified as Aboriginal in the overall sample of 448 sentencing remarks where judges did not acknowledge trauma. In none of these cases did the judge explicitly recognise a lack of ACEs or traumatic life events; rather, the sentencing remarks were silent regarding trauma. All these Aboriginal defendants were male, with varied principal offences (i.e., robbery, two assaults, driving causing harm, firearms offences, and drug trafficking). Five of the six defendants were aged between 35 and 41 , with the age of one defendant unknown. All the defendants had extensive criminal 
histories. While it is possible that none of the defendants had been exposed to trauma in their lives, it is more likely that the judges assumed that after at least 20 years of adulthood and decades of offending behaviour, developmental trauma was no longer worth mentioning nor relevant to sentencing.

Once the sample of Aboriginal defendants with trauma histories was identified, the sentencing remarks were manually reviewed to determine when judges made explicit statements recognising an association between defendant trauma and offending behaviour. In terms of identifying a trauma-informed response, proxy measures were developed from the manifest content of sentencing remarks, as follows:

- judges referred to defendants directly and by name (safety);

- judges explained an element of the sentencing process to the defendant (trustworthiness and transparency);

- judges asked the defendant whether they understood the sentencing outcome (safety, empowerment);

- judges asked the defendant whether they accept and would abide by the sentencing decision (choice and empowerment, collaboration).

In determining whether a trauma-informed sanction was imposed, sentencing remarks were analysed to identify when an overt statement was made by the judge indicating an adjustment of sanction had been made in response to the defendant's trauma history. Finally, a judge's intention to resist further re-traumatisation was based on specific statements in sentencing remarks where the judge sought to avoid further trauma for the defendant or the defendant's family.

\section{Results}

\section{Sentencing Remarks Where Judges Realised Defendant Trauma Was Present}

Judges realised that traumatic events and experiences were present in the lives of 36 defendants identified as Aboriginal ( $85.7 \%$ of the Aboriginal sample), including nine females $(16.4 \%$ of traumatised women; $25.0 \%$ of traumatised defendants identified as Aboriginal). Across the lifespans of 31 defendants, judges noted complex and chronic trauma, including exposure to domestic abuse as a child, parental substance abuse, the deaths of loved ones, child abuse and neglect, and parental absence and abandonment. For example:

[Y]ou yourself had a terrible background. I will not set out in detail the disadvantages that you have suffered but they are considerable ... your mother 
"Qualitative Criminology" Using a Trauma-Informed Practice Framework to Examine How South Australian Judges Respond to Trauma ...

and stepfather abused you in just about every way imaginable. They neglected you, they both abused you physically and sexually. (R $\vee D L H)$

You had a rough childhood marked by chronic instability, neglect and dysfunction ... You were exposed to alcohol abuse and illicit drug use from an early age. There was always domestic violence in the home. Not surprisingly, your education was very disrupted and you are illiterate. ( $R \vee D G)$

You ... left school in about year $9 \ldots$ your schooling life was characterised by being bullied and your home life was plagued with alcohol and violence. From a relationship that began when you were very young, you have four children who range in ages from nine through to 19 . You say your relationship was characterised by domestic violence and alcohol abuse, which led to [Child Protection authorities] ordering your two eldest daughters to live with your parents ... you returned to using alcohol and illicit drugs ... you were heavily pregnant and granted home detention bail ... You were eventually rushed to the hospital for an emergency caesarean, however your child was stillborn. You were then returned to custody where you have remained. ( $R \vee K K)$

You grew up in a household marred by excessive alcohol use and violence. Your parents separated when you were five years of age. Your mother struggled to raise your family by herself and she relied on the help of relatives. Your older brother passed away when you were 10 years of age ... Your mother passed away when you were 17; her passing devastated you ... (R $\vee$ CLS)

You are the product of a devastating long-term effect of serial childhood abuse of one sort or another. There is no doubt you have been a victim of abuse and neglect since a very young age. Yours is a very tragic background. (R $\vee A B T)$

Judges identified single-incident trauma in the sentencing remarks of five defendants. One judge simply referred to "past traumas at the age of between 10 and 12 years" (R $\vee$ CPM). In another case, Judge \#11 noted that the defendant, a "traditional initiated man," was traumatised by the murder of his sister (R v MDG). In the sentencing remarks of three other defendants, the judges only acknowledged trauma in adulthood. One man was exposed to violence as a member of an Outlaw Motorcycle Club (R v NDK). One woman was the victim of domestic abuse as an adult ( $R \vee I N)$. Another woman was denied access to her children by her ex-partner ( $\mathrm{R} \vee \mathrm{CLDS}$ ). 
There were only 13 defendants (36.1\% of traumatised Aboriginal defendants) for whom a link was made by a judge between the traumatic impact of adversity and criminal behaviour. Judges typically recognised a relationship between ACEs, substance abuse and criminal behaviour. In some cases, this link was not considered causal but rather as something that "explains, but does not excuse the offending" (R v SWT). It was common for judges to recognise that alcohol and illicit drugs were relied upon by defendants to self-medicate to help deal with traumatic distress. For example, one defendant had an extensive trauma history. When his victim shared intimate images of the defendant, this led to multiple attempts of suicide as well as his offending behaviour. The judge noted that " ... you received [a] diagnosis of post-traumatic stress disorder ... [and] sought to self-medicate by taking drugs, in particular methylamphetamine" (R v WLT). In sentencing another man, Judge \#18 noted that he had experienced complex trauma as a child and self-medicated as a result.

Your mother ... died tragically when she was only 19 in a motor vehicle accident. At that time, you were four and your younger sisters were three and two. You have had no connection with your father. You and your siblings were left to be raised by various family members and were separated from each other ... you had no attachment to any ongoing positive role models ... You have been addicted to cannabis since your mid-20s, that is in part the reason for this offending. ( $R \vee \mathrm{KJL}$ )

Similarly, judges recognised that defendants' experiences of grief and loss after the (often unexpected) deaths of family members were pre-cursors to substance abuse and subsequent offending. In sentencing Ms RK, the judge stated:

[T]he death of your niece and her children in 2016 led to an understandable grief reaction and an increase in your dependence on substances. That was, no doubt, a contributing factor to the breaching offences as well, which occurred only a week or so after the suspended sentence was imposed, as I have already said. Your grief had obviously not resolved by then[.] (R $\vee R E K)$

Judge \#7 found that Mr ST was dealing with his own unresolved grief and "had turned to drugs to try to take away your pain. You offended because you needed money to pay for more drugs to feed your habit" (R $\vee S W T)$.

In the sentencing remarks of Ms B, the judge extensively cited a psychiatric report that linked the defendant's trauma history with her offending behaviour through the resulting personality disorder and methamphetamine use disorder. Judge \#10 noted that: 
"Qualitative Criminology"

$\operatorname{Dr}[\mathrm{X}]$ diagnosed you as suffering from borderline personality disorder which she described as a long-standing maladaptive pattern of behaving and feeling, with associated instability in moods, behaviour, self-image and functioning. $\mathrm{Dr}[\mathrm{X}]$ recorded that these experiences often resulted in impulsive actions such as outbursts of anger, deliberate self-harm, unstable interpersonal relationships, extreme sensitivity to abandonment, depression and anxiety.

In $\operatorname{Dr}[X]$ 's opinion this can be traced back to your childhood, where you were exposed to trauma such as neglect, abuse and domestic violence.

$\operatorname{Dr}[\mathrm{X}]$ 's view is that it is highly likely that your offending occurred as a result, at least in part, to your methamphetamine addiction and intoxication at the time. In $\operatorname{Dr}[\mathrm{X}]$ 's opinion, you manage stressful periods by using substances. This is perpetuated by the ready availability of those substances and the common nature of drug use in your family and friendship circles. In times of extreme stress, you have self-harmed by cutting or taking large amount of pills ... $\operatorname{Dr}[X]$ views the major risk factor in your case for recidivism and involvement in violent offending is methamphetamine use. ( $R \vee M B)$

In sentencing Mr MW, the judge noted multiple traumas in MW's childhood and that his mental health issues were affected by his drug use. The judge noted:

Your father died when you were a young child and unfortunately your mother was murdered when you were a teenager ... You also lost your elder sister three years ago from an epileptic fit. You were present when she passed away ... You started smoking marijuana at the age of 16 and used it daily up until you were incarcerated. At the age of 15 you started to drink alcohol. Very unfortunately, at the age of 19 you started to use ice ... You have a history of mental health issues. It is plain they are greatly exacerbated by your drug and alcohol abuse ... This offending happened in large part because of the weeks of cannabis, methamphetamine and alcohol use, which had resulted in the state you were in that morning, which meant you behaved so much more dangerously and irresponsibly than you would have normally. ( $R \vee M E W)$

Mr BT also had a chaotic and dysfunctional childhood. In sentencing him, Judge \#3 acknowledged a direct link between his unresolved developmental trauma and offending behaviour; in addition to acknowledging the role of substance abuse. The judge said: 
[Y]our historical violent and reckless behaviours appear to have emanated from your chaotic and unstable childhood environment, in the absence of strong prosocial influences and role models. Furthermore, the majority of your past offending behaviours have reportedly been precipitated by your substance abuse. $(\mathrm{R} \vee \mathrm{BTT})$

Judges identified an association between unresolved developmental trauma and crime in one-third of the sentencing remarks of Aboriginal defendants. Judges identified how trauma impacted Aboriginal people's coping skills and functioning, and trauma had led to, and been exacerbated by, substance abuse. Judges more often accepted that complex trauma was associated with substance abuse and the substance abuse led to the offending behaviour, without necessarily making a causal link between the unresolved trauma and substance abuse. Judges also recognised that defendants who had developmental trauma lacked the ability to cope with new stressors without alcohol and drugs, such as adult-onset adversity, like the death of a loved one.

\section{Judges' Responses to Trauma in the Lives of Aboriginal Defendants}

A trauma-informed response may be evident in either the sentencing process and/or the sentencing sanction. For seven defendants, where judges realised that trauma was present in their lives there were no indicators in the sentencing remarks that the sentencing process or sanction were informed by trauma. This was despite judges recognising in five cases that the defendants' trauma was associated with their criminal behaviour. Overall, there were elements of trauma-informed practice in the sentencing of 26 Aboriginal defendants (i.e., sentencing remarks of 11 defendants contained no indicators of trauma-informed practice). Within the sample of sentencing remarks:

- Judges referred to 26 defendants directly and by name (not just at the opening of the sentencing remarks; $72.2 \%)$. For five defendants, this was the only procedural indicator of trauma-informed principles in practice.

- Judges explained an element of the sentencing process to the 17 defendants (45.9\%).

- Judges asked seven (18.9\%) defendants whether they understood the sentencing outcome, (mainly when the judges were imposing bonds).

- Judges asked seven defendants whether they accept and will abide by the sentencing decision.

There was one case where the judge amended his sentencing sanction after discussion with the defendant, as illustrated in the following excerpt. 
"Qualitative Criminology" Using a Trauma-Informed Practice Framework to Examine How South Australian Judges Respond to Trauma ...

Ms CLDS, are you willing to enter into a bond in those conditions, suspending the prison sentence that I have passed upon you?

PRISONER Your Honour, I've put in for a job [interstate ]... The only reason why I'm still here in South Australia is because of my court thing but once this was dealt with I was just going to sort of leave - leave, so - but whatever your Honour says, I'll do.

HIS HONOUR When is it your intention to leave South Australia for [interstate]?

PRISONER As soon as my court thing was dealt with ...

HIS HONOUR All right then, against my better judgment, I will withdraw the condition that you be under the supervision of a Community Corrections Officer because that will mean that you would not be able to leave the State of South Australia, do you understand?

\section{PRISONER NODDING}

HIS HONOUR Let's make this very clear, Ms CLDS: you are on a suspended sentence. If you commit any further offences whilst you are subject to that suspended sentence then there will be an application to revoke the suspension and, if granted, that will mean you will be sent to prison to serve this sentence of 12 months and 18 days imprisonment with a non-parole period of six months, on top of any other sentence the court imposes for any offences that breach the suspended sentence. Do you understand?

PRISONER Yes.

HIS HONOUR Can you just repeat to me what will happen to you if you commit further offences during the term of this bond.

PRISONER I will be going to gaol for 12 months.

HIS HONOUR As long as we understand each other and as long as you understand the consequence of non-compliance with the good behaviour condition of the bond. All right, come forward then to acknowledge the bond.

BOND ACKNOWLEDGED ( $\mathrm{R} \vee \mathrm{CLDS}$ ) 
Of the 36 Aboriginal defendants with trauma histories, 28 defendants (77.8\%) were imprisoned, one received home detention, six received suspended sentences, and one defendant received no further penalty. Thirteen defendants received trauma-informed sanctions. A trauma-informed sanction was not necessarily a non-custodial sentence. Twelve defendants were incarcerated, and one received a suspended sentence in cases where judges had explicitly imposed sanctions informed by trauma. Instead, in five cases, when a judge recognised the relevance of a defendant's trauma history, they imposed a shorter than usual non-parole period, often with the stated intention to facilitate access to rehabilitation programs. In sentencing Mr K, Judge \#14 said:

I cannot give you a guarantee but I am very, very hopeful that you will be released as soon as you have served your non-parole period to take up the place with the Aboriginal Sobriety Group [at Lakalinjeri Tumbetin Waal (LTW), a live-in rehabilitation centre at Monarto]. (R v NDK)

Similarly, in sentencing Mr CM, Judge \#24 focused on rehabilitation, and said:

You are clearly in need of further treatment, particularly for the substance abuse disorder.

It is here that your personal circumstances come into sharp focus. You come before the court as an indigenous man without any prior convictions bearing much resemblance to the current state of offences and at an age when it is likely you are reconsidering the direction of your future life. As mentioned, you are directing your energy towards an emerging motivation for treatment and reform.

In the combined circumstances, a merciful non-parole period of two years and nine months is set. ( $R \vee C P M)$

Mr MW also received a shorter than usual non-parole period after being incarcerated for a serious assault, since he had "made a good start towards getting your life back on track, in that you have been clean of drugs while in custody" and demonstrated remorse for his actions ( $R v M E W$ ). In sentencing Mr MG, Judge \#11 stated that "I also accept that you are a traditional Aboriginal man and that it is hard for you in custody." While she did not explicitly state that she was imposing a shorter than usual sentence, Judge \#11 imposed a relatively short sentence, effectively extending his existing non-parole period by a month ( $R \vee M D G)$.

Some judges recommended a longer period on parole under supervision in the community. For example, in sentencing Ms RK, Judge \#2 stated: 
"Qualitative Criminology" Using a Trauma-Informed Practice Framework to Examine How South Australian Judges Respond to Trauma ...

Having given the matter careful thought, I have formed the view that special circumstances exist in relation to your personal situation. I particularly note your unresolved grief relating, as I said, to the tragic loss of your family members in 2016 and your ongoing battle with substance abuse.

I consider these issues are substantial and were no doubt significant contributors to your breach of your bond.

In those circumstances, and pursuant to s.114(5)(a) of the Sentencing Act, I reduce that sentence from one year, four months and seven days to 10 months imprisonment. ( $R \vee R E K)$

Personal circumstances, including age, also influenced how judges used trauma information when imposing a sanction. For example, young adult offenders were likely to receive a shorter non-parole period. Age was cited by Judge \#11 when sentencing Ms KM. She said:

I take into account your youth, the fact that you have never spent time in an adult gaol before, the need to promote your rehabilitation and I do think you have developed some insight into the seriousness of your offending, as well as the need to take advantage of the support that is now being offered to you.

... I will not sentence you as a serious repeat offender.

In fixing the non-parole period, I am able to give greater emphasis to your personal circumstances. They are particularly your youth and, as I said, I think you have developed some insight and desire to rehabilitate yourself.

You, too, need to spend a lengthy period of time in the community under supervised parole. That is to protect the safety of the community and help you rehabilitate yourself. ( $R \vee K L M)$

In one case, the judge identified the presence of trauma but rejected submissions from defence counsel and a forensic psychologist that the defendant's personal circumstances should influence the sanction imposed. In this case, the judge said:

You have suffered deprivation and the trauma of witnessing ongoing violence, the effects of which are no doubt ongoing ... I have considered the submission carefully ... Leniency previously extended to you has not deterred you from violent 
offending and unfortunately I can have little confidence that there will be no further offending. ( $R \vee S E W)$

\section{Resisting Re-Traumatisation of the Defendants and Their Families}

There were nine cases where judges acknowledged that a lengthy prison sentence would lead to re-traumatisation, either of the defendants, their family, or children. In sentencing Mr WT, Judge \#5 imposed a suspended sentence, stating:

You have taken some, albeit halting, steps towards your own rehabilitation. You have family responsibilities, particularly for your autistic son. I do not think that any one of these reasons taken alone amounts to good reason to suspend the sentence, but, in combination, I find that they do. (R $\vee$ WLT)

Additionally, in the sentencing remarks of three defendants, judges recognised that prison is particularly hard on Aboriginal people. For example, in the case of Mr MG, Judge \#11 said, "I also accept that you are a traditional Aboriginal man and that it is hard for you in custody" ( $\mathrm{R} \vee \mathrm{MDG})$.

\section{Discussion}

By applying a trauma-informed framework to sentencing remarks of Aboriginal defendants, this article reflected on whether the sentencing practices of South Australian judges were informed by trauma. When judges identified defendants as Aboriginal, they realised that trauma was present in the lives of most defendants, as per Figure 2 below. However, judges only recognised direct trauma experiences, such as the deaths of loved ones, child abuse and neglect, and parental absence and abandonment. Judges did not acknowledge any examples of collective or intergenerational trauma associated with the defendants' Aboriginality. In addition, few judges recognised a link between defendant trauma and offending behaviour. Often judges used trauma-informed practices in court when responding to traumatised defendants, although these could "merely reflect good practice in ensuring defendants have participatory rights in the court process" (McLachlan, 2021, p. 14), particularly given that the Australian Guide to Judicial Conduct requires judicial practices that are respectful of defendants (Australian Institute of Judicial Administration, 2017). In approximately one-third of cases, the sanctions imposed by judges were explicitly influenced by defendants' trauma histories, and in nine cases, the judges intentionally worked to avoid further re-traumatisation for the defendant and/or their children. As can be seen from Figure 2, the application of the trauma-informed framework was not a linear process or process of attrition but rather more of a concertina effect. 
Figure 2: Trauma-informed practice framework applied to sentencing remarks

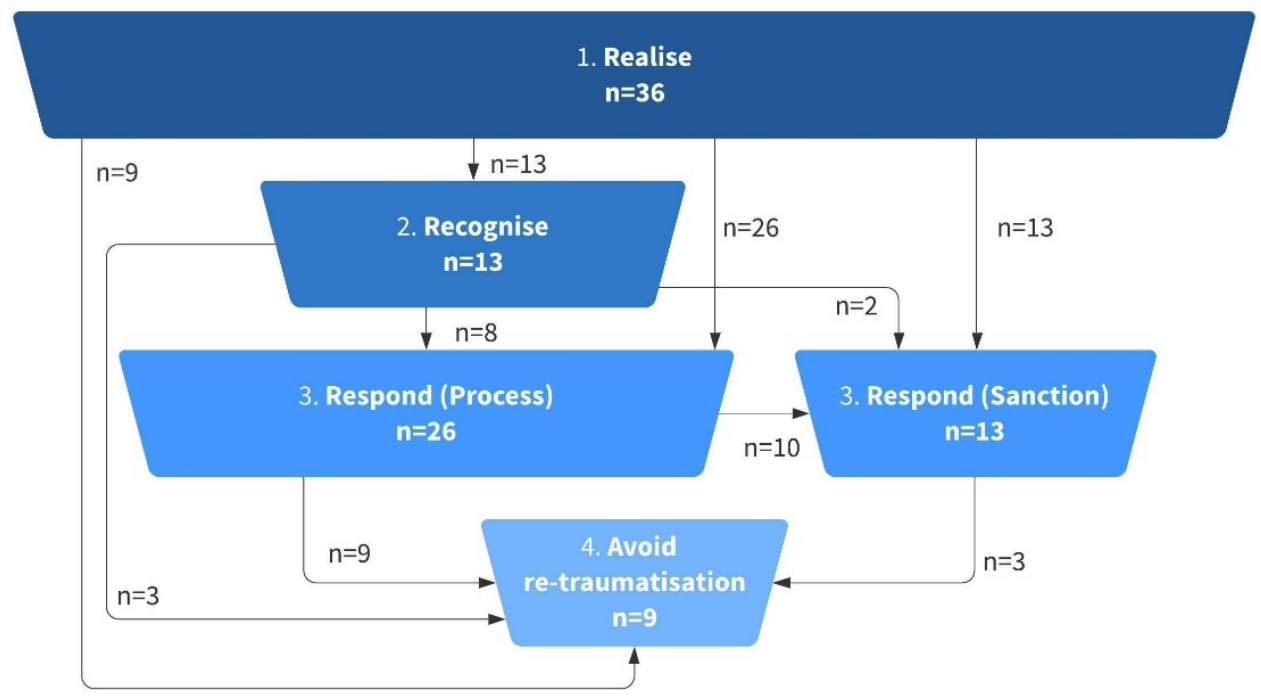

In Figure 3, the trauma-informed framework has been applied individually to each of the 42 Aboriginal defendants. Each defendant is represented as a single horizontal line, with dark shading indicating trauma-informed practice. A completely traumainformed sentencing experience would require shading in all five broad columns. The diagram shows no single Aboriginal defendant received a sentencing response that realised, recognised, and responded to their trauma as well as resisting re-traumatisation. There were eight defendants (19.0\% of Aboriginal defendants) who received a sentencing response that was mostly informed by trauma.

- $\quad$ For two defendants, trauma was realised, recognised, and responded to, but there was no discussion about resisting re-traumatisation.

- While trauma was realised, recognised, and responded to in an informed way, the sanctions imposed on three defendants were not trauma-informed.

- $\quad$ Three defendants received a mostly trauma-informed sentencing response but there was no recognition of a trauma-crime relationship.

This analysis highlights that wholly trauma-informed practice is not common, when sentencing Aboriginal defendants. 
Figure 3: The Application of the Trauma-Informed Framework in the Sentencing of Each Defendant (Shading Indicates Trauma Informed Practice).

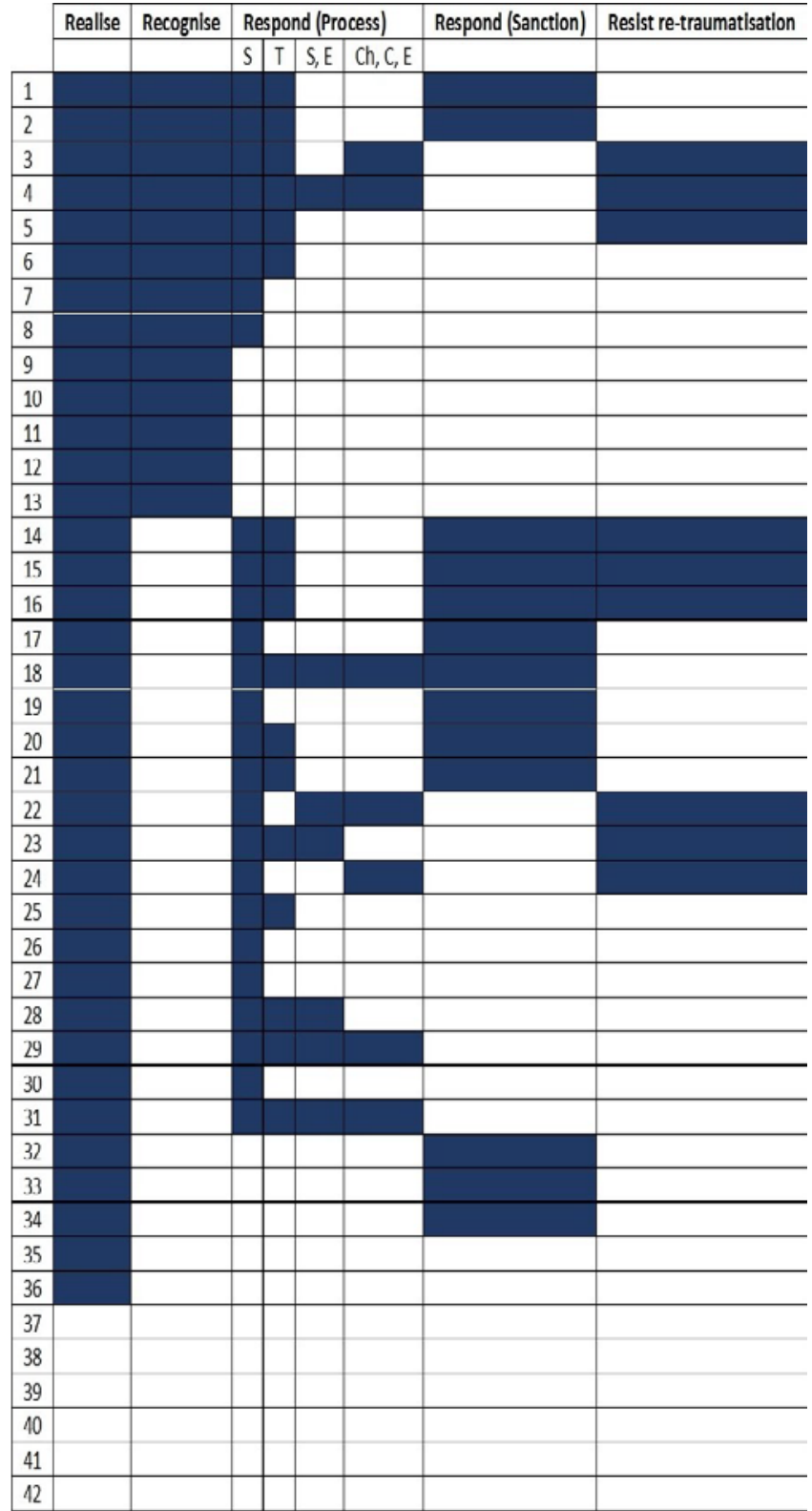

Note: $\mathrm{S}=$ Safety; $\mathrm{T}$ = Trust and transparency; $\mathrm{Ch}=$ Choice; $\mathrm{C}=$ Collaboration; $\mathrm{E}=$ Empowerment. 
"Qualitative Criminology"

Given this study is based on analysis of manifest content in sentencing remarks, judges' statements were used to identify Aboriginal defendants. The analysis shows that even when judges identified defendants as Aboriginal people, they overlooked or paid minimal attention to cultural factors in sentencing. When sentencing a traumatised defendant who they identified as Aboriginal, judges avoided overtly attributing trauma to any cultural, historical, or intergenerational trauma known to be associated with Aboriginality. Although most Aboriginal defendants were found to have had a history of traumatic experiences and events, judges made a link between trauma and criminal behaviour in only a third of sentencing remarks. While judges are bound by legal precedent that diminishes the relevance of cultural trauma (e.g., Bugmy $v$ The Queen), cases are emerging where Australian judges have acknowledged the potential relevance of historical and intergenerational trauma experienced by Aboriginal defendants (Cooper, 2020; DPP v Herrmann [2021]).

Judges are bound under law to give regard to individual sentencing factors, including the "defendant's general background" (Sentencing Act 2017, s 11(1)(d)). The larger sample of sentencing remarks included remarks pertaining to Aboriginal defendants - a fact I know from my work with the Parole Board and was likely to also be known to at least some of the sentencing judges. That sentencing remarks did not acknowledge a defendant's cultural heritage does not mean that Aboriginality was not taken into consideration by the judge. Judges would be aware of the over-representation of Aboriginal people in the criminal justice system (Productivity Commission, 2021). By not acknowledging defendants' Aboriginality in their remarks, judges may have sought to avoid being perceived as racist, or biased (Barry, 2021; Jeffries \& Bond, 2009), regardless of whether they did take Aboriginality into account in sentencing. Similarly, while no definitive conclusions can be made, it is reasonable to assume that some sentencing decisions within the sample may have been influenced by judges' understanding of intergenerational and historical trauma, even when judges did not make overt reference in their remarks. What is certain is that sentencing remarks should be a more complete summary of the sentencing factors. As highlighted in their research referring to mitigating or aggravating factors, Warner and colleagues (2018, p. 63f) emphasised the importance of judicial remarks being "less cryptic," to enable parties and community members to better understand their sentencing rationale.

\section{Implications}

\section{Qualitative Criminology}

Further research involving interviews with members of the judiciary could assist in developing a better understanding of the degree to which judges currently understand the 
impact of intergenerational and culturally-related trauma on the wellbeing and behaviour of Aboriginal defendants and how judges perceive trauma information and culture influences their sentencing decision-making.

Given the high number of Aboriginal defendants identified by judges as traumatised, and indeed the high number of defendants overall with histories of trauma, it would be valuable to interview judges to determine why they appear reticent to recognise an association between trauma and criminal behaviour.

\section{Quantitative Criminology}

While there are emerging trauma-informed correctional care practices with women and children, often adult men are overlooked as a highly traumatised population. Better data are required to identify justice-involved Aboriginal people who have been impacted by intergenerational and historical trauma as well as their own direct experiences of traumatic events. Quantitative research could also map the pathways in and out of the child protection, youth justice and criminal justice systems, to identify opportunities for earlier and more effective support and interventions to break the cycle of offending and re-traumatisation.

Further research is also needed regarding 'what works' in terms of effective, trauma-informed, evidence-informed, culturally appropriate sanctions that can reduce future offending as well as resist re-traumatisation of defendants and their children and families.

\section{Policy and Practice}

While courts currently recognise trauma in sentencing (most often about victims, but also defendants), trauma research is evolving more quickly than lay understandings of counsel and judicial officers. This research indicates that judges are more likely to consider the impact of direct complex trauma on criminal behaviour, than intergenerational trauma. There are early indicators in Australia that judges are recognising the gaps in their understanding and the need for cultural advice and are beginning to request "Indigenous Experience Reports" (ALRC, 2017, p. 2014) akin to "Gladue Reports" in Canada, to better understand the role that compound trauma plays in the offending behaviour of Aboriginal and Torres Strait Islander defendants (see: Cooper, 2020). Judges also seemed unsure of the best sanction to impose to achieve community safety, the principal sentencing purpose in South Australia (as per Sentencing Act 2017, s 3). As a result, most often judges impose short-term incarceration, which can be just long enough for defendants to 
"Qualitative Criminology"

lose a job, rental accommodation, a relationship, and access to children, effectively ensuring re-traumatisation on release.

If sentencing remarks are misrepresenting the degree to which judges are giving regard to a defendant's Aboriginality or applying a trauma-informed lens to their work, then judges need to ensure that their remarks are comprehensive enough that they do reflect the ways in which information about defendant culture and trauma has been used. There is a need for the development of judicial education and resources (such as an online Bench book) to explain the significance of trauma in sentencing decision-making, the importance of culturally appropriate and trauma-informed sentencing and examples of evidence-based behaviour change and rehabilitative strategies and programs. Judges need greater awareness of Justice Reinvestment strategies and initiatives that divert spending and resources away from incarceration into evidence-based, trauma-informed, locally developed solutions to help address unresolved trauma and reduce the overrepresentation of Indigenous people in the criminal justice system.

\section{Conclusion}

SAMHSA's trauma-informed practice framework was used to examine how judges of South Australian superior courts acknowledge defendant trauma when sentencing Aboriginal defendants. From the sample of sentencing remarks, it is evident that judges realised many Aboriginal defendants have experienced direct, unresolved complex trauma, but none recognised the relevance of collective, intergenerational trauma. Judges recognised in one-third of cases that exposure to traumatic experiences often led to the misuse of alcohol and illicit drugs, and substance abuse is associated with other criminal behaviour, but rarely acknowledged that trauma led to or was causative of crime per se. While many judges employed court practices that could be deemed trauma-informed and reflected trauma-informed principles of practice, few imposed sanctions that were informed by trauma or acknowledged the traumatic impact of imprisonment on defendants or their families. In most cases, where trauma was acknowledged in the sentencing of Aboriginal defendants, this led to a reduction in the period of incarceration. Overall, there were no cases where a defendant received a wholly trauma-informed sentencing response.

\section{References}

Atkinson, C.L. (2008). The violence continuum: Australian Aboriginal male violence and generational post-traumatic stress, [Unpublished PhD Thesis]. Charles Darwin University. 
Atkinson, J., Nelson, J., Brooks, R., Atkinson, C., \& Ryan, K. (2014). Addressing individual and community transgenerational trauma. In P. Dudgeon, H. Milroy \& R. Walker (Eds.), Working together: Aboriginal and Torres Strait Islander mental health and wellbeing principles and practice. (2 ${ }^{\text {nd }}$ ed, pp. 289-305). Commonwealth of Australia.

Australian Bureau of Statistics (2019). 2071.0 - Census of population and housing: Reflecting Australia - Stories from the census, 2016.

Australian Institute of Judicial Administration (2017). Guide to judicial conduct. ( ${ }^{\text {rd }}$ ed).

Australian Institute of Health and Welfare (2018). Aboriginal and Torres Strait Islander Stolen Generations and descendants: Numbers, demographic characteristics and selected outcomes. (Cat. No. IHW 195). https://www.aihw.gov.au/getmedia/a6c077c3e1af-40de-847f-e8a3e3456c44/aihw-ihw-195.pdf.aspx?inline=true

Australian Law Reform Commission (2017). Pathways to justice-An inquiry into the incarceration rate of Aboriginal and Torres Strait Islander peoples: Final report. (Report No 133).

Barry, B.M. (2021) How judges judge: Empirical insights into judicial decision-making. Routledge.

Berryessa, C.M. (2021). The potential influence of criminological rationales in considering childhood abuse as mitigating to sentencing. Child Abuse \& Neglect, 111(104818), 1-14.

Bombay, A., Matheson K., \& Anisman, H. (2009). Intergenerational trauma: Convergence of multiple processes among First Nations peoples in Canada. Journal of Aboriginal Health, 5(3), 6-47.

Bond, C., \& Jeffries, S., (2013). Differential sentencing of Indigenous offenders: What does research tell us? Indigenous Law Bulletin, 8(7), 15-18.

Boswell, G., (2016). Trauma experiences in the backgrounds of violent young offenders. Pakistan Journal of Criminology, 8(2), 12-24.

Braun, V., \& Clarke, V. (2006). Using thematic analysis in psychology. Qualitative Research in Psychology, 3, 77-101. 
Cloitre, M., Stolbach, B.C., Herman, J.L., van der Kolk, B., Pynoos, R., Wang, J., \& Petkova, E (2009). A developmental approach to complex PTSD: Childhood and adult cumulative trauma as predictors of symptom complexity. Journal of Traumatic Stress, 22(5), 399-408.

Cooper, A. (2020, December 17). Indigenous disadvantage a focus in sentence appeal for Aiia's killer. The Age. https://www.theage.com.au/national/victoria/indigenousdisadvantage-a-focus-in-sentence-appeal-for-aiia-s-killer-20201217-p56ock.html

Courts Administration Authority (2019). Sentencing remarks. CAA. https://www.courts.sa.gov.au/court-decisions/sentencing-remarks/

Covington, S.S. (2016). Becoming Trauma Informed: Tool Kit for Women's Community Service Providers. One Small Thing.

Dodson, M. (1997). Citizenship in Australia: An Indigenous perspective. Alternative Law Journal, 22(2), 57- 59.

Fallot, R.D., \& Harris, M., (2011). Creating cultures of trauma-informed care (CCTIC): A self-assessment and planning protocol. (Version 2.3). Community Connections.

Felitti, V.L., Anda, R.F., Nordenberg, D., Williamson, D.F., Spitz, A.M., Edwards, V., Koss, M.P., \& Marks, J.S. (1998). Relationship of childhood abuse and household dysfunction to many of the leading causes of death in adults: The Adverse Childhood Experiences (ACE) study. American Journal of Preventive Medicine, 14(4), 245-258.

Ford, J.D., \& Courtois, C.A. (2014). Defining and understanding complex trauma and complex traumatic stress disorders. In C.A. Courtois \& J.D. Ford (Eds.), Treating complex traumatic stress disorders: Scientific foundations and therapeutic models (pp. 13-30). Guilford.

Freiberg, A. Payne, J., Gelb, K., Morgan, A., \& Makkai, T. (2016). Drug and specialist courts review. Queensland Department of Justice and Attorney-General.

Harris, M., \& Fallot, R. (2001). Envisioning a trauma-informed service system: A vital paradigm shift New Directions for Mental Health Services, 2001(89), 3-22.

Henderson, C., Everett, M., \& Isobel, S. (2018). Trauma-informed care and practice organisational toolkit (TICPOT): An organisational change process resource, Stage 1 Planning and audit, Mental Health Coordinating Council. 
Higgins, D.J., \& McCabe, M.P. (2001). Multiple forms of child abuse and neglect: Adult retrospective reports. Aggression and Violent Behavior, 6, 547-578.

Hill, J.S., Lau, M.Y., \& Sue, D.W. (2010). Integrating trauma psychology and cultural psychology: Indigenous perspectives on theory, research, and practice. Traumatology, 16(4), 39-47.

Hytner, M., (2021, 21 January). Scott Morrison criticised for saying 26 January 'wasn't a flash day for those on first fleet vessels either'. The Guardian. https://www.theguardian.com/sport/2021/jan/21/australia-day-references-dropped-withbig-bash-cricketers-to-wear-indigenous-strips

Jeffries, S., \& Bond, C., (2009). Does Indigeneity matter? Sentencing Indigenous offenders in South Australia's higher courts. Australian and New Zealand Journal of Criminology, 42(1), 47-71.

Jones, L. (2018). Trauma-informed care and 'good lives' in confinement: Acknowledging and offsetting adverse impacts of chronic trauma and loss of liberty. In G. Akerman, A. Needs \& C. Bainbridge (Eds.), Transforming environments and rehabilitation: A guide for practitioners in forensic settings and criminal justice. (pp. 92-114). Routledge.

Judicial College of Victoria (2020). Victorian Sentencing Manual (4 ${ }^{\text {th }}$ ed.). https://resources.judicialcollege.vic.edu.au/article/669236

Kezelman, C., Hossack, N., Stavropoulos, P., \& Burley, P. (2015). The cost of unresolved childhood trauma and abuse in adults in Australia. Adults Surviving Child Abuse and Pegasus Economics.

Kezelman, C., \& Stavrolpoulos, P. (2019). Practice guidelines for clinical treatment of complex trauma. Blue Knot Foundation.

Kezelman, C., \& Stavrolpoulos, P. (2016). Trauma and the law: applying trauma-informed practice to legal and judicial contexts. Blue Knot Foundation.

Kim, S., Fonagy, P., Allen, J., \& Strathearn, L., (2014). Mothers' unresolved trauma blunts amygdala response to infant distress. Social Neuroscience, 9(4), 352-363.

Kubiak, S.P., Covington, S.S., \& Hillier, C (2017). Trauma-informed corrections. In D. Springer and A. Robert (Eds.), Social work in juvenile and criminal justice systems. (pp. 92-104). Charles Thomas. 
Malvaso, C. G., Cale, J., Whitten, T., Day, A., Singh, S., Hackett, L., Delfabbro, P. H., \& Ross, S. (2021). Associations between adverse childhood experiences and trauma among young people who offend: A systematic literature review. Trauma, Violence \& Abuse, Advance online publication, 1-18.

Maxfield, M.G., \& Babbie, E. (2006). Basics of research methods for criminal justice and criminology. Thomson Wadsworth.

McLachlan, K.J. (2021). Same, same or different? Is trauma-informed sentencing a form of therapeutic jurisprudence? European Journal of Current Legal Issues, 25(1), 1-20.

Menzies, K. (2019). Understanding the Australian Aboriginal experience of collective, historical and intergenerational trauma. International Social Work, 62(6), 1522-1534.

Minh, A., Matheson, F.I., Daoud, N., Hamilton-Wright, S., Pedersen, C., Borenstein, H., \& O'Campo, P. (2013) Linking childhood and adult criminality: Using a life course framework to examine childhood abuse and neglect, substance use and adult partner violence. International Journal of Environmental Research and Public Health, 10(11), 5470-5489.

Ministry of Justice (2013). Transforming rehabilitation: A summary of evidence on reducing reoffending. Crown.

Productivity Commission (2021). Corrective services. In Productivity Commission (Ed.), Report on Government Services 2021 Part C: Justice. (Chapter 8). Australian Government.

Productivity Commission (2016). Overcoming Indigenous disadvantage: Key indicators 2016 report. Commonwealth of Australia.

Quiros, L., Varghese, R., \& Vanidestine, T. (2020). Disrupting the single story: Challenging dominant trauma narratives through a critical race lens. Traumatology, 26(2), 160-168.

Reavis, J.A., Looman, J., Franco, K. A., \& Rojas, B. (2013). Adverse childhood experiences and adult criminality: how long must we live before we possess our own lives? The Permanente Journal, 17(2), 44-48. 
Shiosaki, E., (2020, February 14). 'I am anxious to have my children home': Recovering letters of love written for Noongar children. The Conversation. https://theconversation.com/friday-essay-i-am-anxious-to-have-my-children-homerecovering-letters-of-love-written-for-noongar-children-127809

Stewart, A., Dennison, S., \& Waterson, E. (2002). Pathways from child maltreatment to juvenile offending. Trends and Issues in Crime and Criminal Justice, 241, 1-6.

Substance Abuse and Mental Health Services Administration (2014). SAMHSA's concept of trauma and guidance for a trauma-informed approach.

van der Kolk, B.A. (1987) The psychological consequences of overwhelming life experiences. In B.A. van der Kolk (Ed.), Psychological Trauma (pp. 1-30) American Psychiatric Press.

van der Kolk, B.A. (2005). Developmental trauma disorder: Towards a rational diagnosis for children with complex trauma histories, Psychiatric Annals, 35(5), 401-408.

Walklate, S. (2016). The metamorphosis of the victim of crime: From crime to culture and the implications for justice. International Journal for Crime, 5(4), 4-16.

Wall, L., \& Quadara, A. (2014). Acknowledging complexity in the impacts of sexual victimisation trauma. ACSSA Issues, 16, 1-24.

Warner, K., Spiranovic, C., Freiberg, A., Davis, J., \& Bartels, L. (2018). Aggravating or mitigating? Comparing judges' and jurors' views on four ambiguous sentencing factors. Journal of Judicial Administration, 28, 51-66.

Weathers, F.W. Blake, D., Schnurr, P., Kaloupek, D., Marx, B., \& Keane, T. (2018). The Life Events Checklist for DSM-5 (LEC-5). (Standard Version). National Center for PTSD.

Wolff, N., \& Shi, J. (2012). Childhood and adult trauma experiences of incarcerated persons and their relationship to adult behavioral health problems and treatment. International Journal of Environmental Research and Public Health, 9(5), 1908-1926.

\section{Case Law}

Bugmy v The Queen (2013) 249 CLR 571

DPP v Herrmann [2021] VSCA 160 
Munda v Western Australia (2013) 302 ALR 207

$R v$ Grose [2014] SASCFC 42

$R$ v Nelson [2017] SASCFC 40

$R$ v Pennington [2015] SASCFC 98

\section{Legislation}

Sentencing Act 2017 (SA)

\section{Sentencing Remarks}

$R v A B T$ (Supreme Court of SA, Justice \#1, 25 September 2019)

$R$ v BTT (District Court of SA, Judge \#3, 6 May 2019)

$R \vee C L D S$ (District Court of SA, Judge \#8, 19 June 2019)

$R$ v CLS (District Court of SA, Judge \#14, 13 June 2019)

$R$ v CPM (District Court of SA, Judge \#24, 19 September 2019)

$R \vee D G$ (District Court of SA, Judge \#18, 26 September 2019)

$R v$ DLH (District Court of SA, Judge \#5, 6 September 2019)

$R \vee I N$ (District Court of SA, Judge \#18, 21 August 2019)

$R v K J L$ (District Court of SA, Judge \#18, 26 September 2019)

$R \vee K K$ (District Court of SA, Judge \#3, 7 May 2019)

$R \vee K L M$ (District Court of SA, Judge \#11, 1 November 2019)

$R \vee M B$ (District Court of SA, Judge \#10, 5 August 2019)

$R$ v MDG (District Court of SA, Judge \#11, 4 June 2019) 
$R$ v MEW (District Court of SA, Judge \#17, 5 August 2019)

$R v$ NDK (District Court of SA, Judge \#14, 7 May 2019)

$R$ v REK (District Court of SA, Judge \#2, 9 August 2019)

$R v$ SCS (District Court of SA, Judge \#24, 17 October 2019)

$R$ V SEW (District Court of SA, Judge \#3, 25 June 2019)

$R v$ SWT (District Court of SA, Judge \#7, 28 August 2019)

$R v W L T$ (District Court of SA, Judge \#5, 3 June 2019)

\section{Contributor}

Katherine J. McLachlan (BA(Hons), LLB(Hons), LLM, GDLP) submitted her PhD thesis in Criminology/Law in October 2021 for assessment. It focused on trauma-informed sentencing. She has more than 20 years' experience working in criminal and social justice roles, with South Australia Police, Attorney-General's Department (SA), the Australian Institute of Criminology and the Australian Centre for Child Protection. She established the online Bachelor of Criminal Justice at the University of South Australia in 2017. Katherine is a third-generation white Australian with Anglo-Celtic ancestors and, without lived experience, has a foundational understanding of the enduring impacts of intergenerational trauma. She has been the victim representative on the Parole Board of South Australia since 2015.

\section{Acknowledgement}

Thank you to Dr Ruth Fazakerley and Andrew Dunlevey for providing insightful comments on early drafts of this paper and to Victoria Parsons for assisting in formatting and editing the final document. 